\title{
Epidemiological investigation of a typhoid fever outbreak in Sekhukhune District, Limpopo province, South Africa - 2017
}

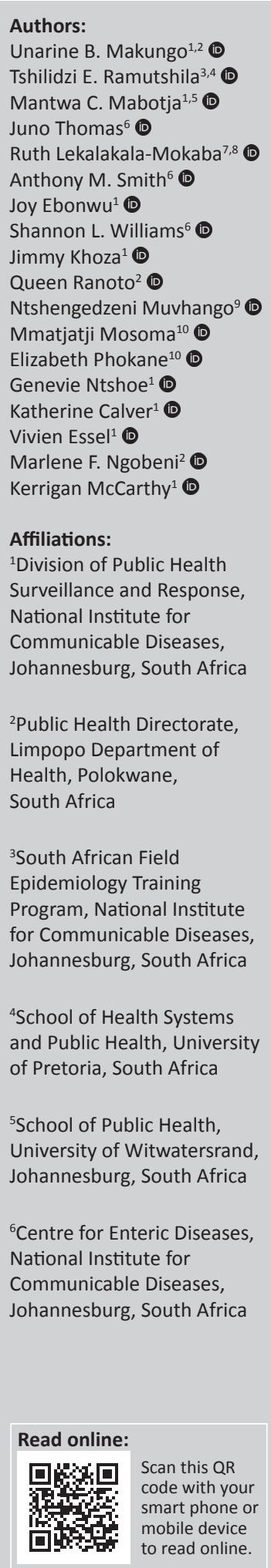

Background: Typhoid fever remains a public health concern in South Africa, where the risk of transmission is high because of poor access to safe water and sanitation. This study describes the investigation of typhoid fever outbreak in Limpopo province.

Methodology: Following notification of laboratory-confirmed cases, a descriptive study was conducted at Sekhukhune District, Limpopo province. A suspected case was defined as any person residing in Makhuduthamaga Municipality from November 2017 to January 2018, presenting with fever and gastrointestinal symptoms. Data were collected using case investigation forms. Whole-genome sequencing (WGS) was carried out on Salmonella Typhi isolates and polymerase chain reaction (PCR) test was done for Salmonella species from water samples. Location of cases and water sources were mapped using ArcGIS mapping tool.

Results: Amongst 122 cases, 54\% $(n=66)$ were female and 6\% $(n=7)$ laboratory-confirmed. The median age of the cases was 11 years (range $2-83$ years), with $79 \%(n=102)$ being children under the age of 14 years. Salmonella species were detected in $37 \%(10 / 27)$ of water samples and geographic information system (GIS) mapping showed clustering of cases in TswaingKgwaripe and Vlakplaas villages. Six isolates were available for WGS analysis, with resulting data showing that five of the six isolates were genetically related. Phylogenetic analysis showed that the five isolates clustered together were genetically related showing $<22$ single nucleotide polymorphisms when compared to each other.

Conclusion: Molecular epidemiology of isolates suggests a common source outbreak, supported by the detection of Salmonella species from water sources. Consumption of water from contaminated open water sources, because of ongoing interruption of municipal water supply, was the likely cause of the outbreak. The investigation highlights the importance of consistent safe water supply and the ability of district surveillance systems to identify and contain outbreaks.

Keywords: typhoid fever; open water sources; outbreak; Limpopo; South Africa.

\section{Introduction}

Water scarcity is ranked as the foremost crisis locally and globally. ${ }^{1}$ South Africa has made a certain degree of improvement on the establishment of sanitation and water quality infrastructures, which has played a fundamental role in the significant reduction of pathogens responsible for water and foodborne illnesses. Despite these improvements, most rural and peri-urban areas experience recurrent water and foodborne disease outbreaks, which have a negative impact on human health. ${ }^{2,3}$ The ongoing state of climate change accompanied by drought has become a fuel for majority of typhoid fever outbreaks in areas with poor sanitation and lack of safe water. ${ }^{4,5,6}$

\footnotetext{
${ }^{7}$ Department of Medical Microbiology, National Health Laboratory Services, Polokwane, Limpopo, South Africa

${ }^{8}$ Department of Medical Microbiology, University of Limpopo, Polokwane, South Africa

${ }^{9}$ Department of Public Health Medicine, Limpopo Department of Health, Polokwane, South Africa

${ }^{10}$ Sekhukhune District, Limpopo Department of Health, Polokwane, South Africa

Research Project Registration:

Project Number: LPREC/19/2018: PG

Corresponding author: Unarine Makungo, unarinem@nicd.ac.za

Dates: Received: 28 May 2019 | Accepted: 07 June 2020 | Published: 16 Nov. 2020

How to cite this article: Makungo UB, Ramutshila TE, Mabotja MC, et al. Epidemiological investigation of a typhoid fever outbreak in Sekhukhune District, Limpopo province, South Africa - 2017. S Afr J Infect Dis. 2020;35(1), a107. https://doi.org/10.4102/sajid.v35i1.107

Copyright: @ 2020. The Authors. Licensee: AOSIS. This work is licensed under the Creative Commons Attribution License.
} 
Typhoid fever is an epidemic-prone disease caused by a gram-negative bacterium, Salmonella Typhi and Salmonella Paratyphi. It is transmitted through consumption of food or water contaminated by faeces or urine of infected persons. Typhoid fever often presents with gastrointestinal symptoms (diarrhoea, abdominal cramps) and life-threatening, enteric febrile systemic illnesses necessitating prompt antibiotic treatment to prevent complications.?

Typhoid fever is a life-threatening disease. Accurate diagnosis in the early stage and effective surveillance are important to ensure early detection and appropriate treatment to mitigate the spread of disease. ${ }^{7}$ A definitive diagnosis of typhoid fever requires the isolation of Salmonella Typhi from blood, bone marrow or a specific anatomical lesion. Blood culture is a recommended diagnostic test of choice given the limitations of testing other specimen types. ${ }^{8}$ Low- and middle-income countries with high typhoid fever endemicity are still using Widal test because it is relatively cheaper and easy to perform. However, the Widal test is not a recommended confirmatory test because of its low sensitivity, specificity and positive predictive value..$^{9,10}$

The World Health Organization (WHO) estimates that approximately 21 million cases and 222000 typhoid-related deaths occur annually worldwide. ${ }^{11}$ South Africa has observed mixed patterns of endemic disease and sporadic cases in more industrialised areas of the country through active laboratory-based surveillance, conducted by GERMSSA of the National Institute for Communicable Diseases (NICD). ${ }^{12}$ The two largest typhoid fever outbreaks in the country occurred in Delmas, Mpumalanga province in 1993 and 2005, where over 1000 and 600 cases were reported, respectively. ${ }^{13}$ However, the number of cases and deaths has declined over the last 22 years, from 6000 cases in 1985 to 200 cases in 2002. ${ }^{12,14}$

On 15 November 2017, Sekhukhune District Department of Health was notified of a laboratory-confirmed Salmonella Typhi case from a tertiary hospital in the province. There were reports of over 20 suspected cases in one of the district hospitals in Sekhukhune District. This led to the activation of the district outbreak response team from 21 November to 31 December 2017. A descriptive epidemiological investigation was conducted to verify the existence of an outbreak, identify the source infection and implement recommendations for the control and prevention of typhoid fever spread in Sekhukhune District.

\section{Methods}

\section{Study design and population}

A cross-sectional descriptive study was conducted to investigate a typhoid fever outbreak amongst 122 patients that presented with clinically compatible illness for typhoid fever at local health facilities in Makhuduthamaga Local Municipality at Sekhukhune District, Limpopo province, from mid-November 2017. Sekhukhune District is divided

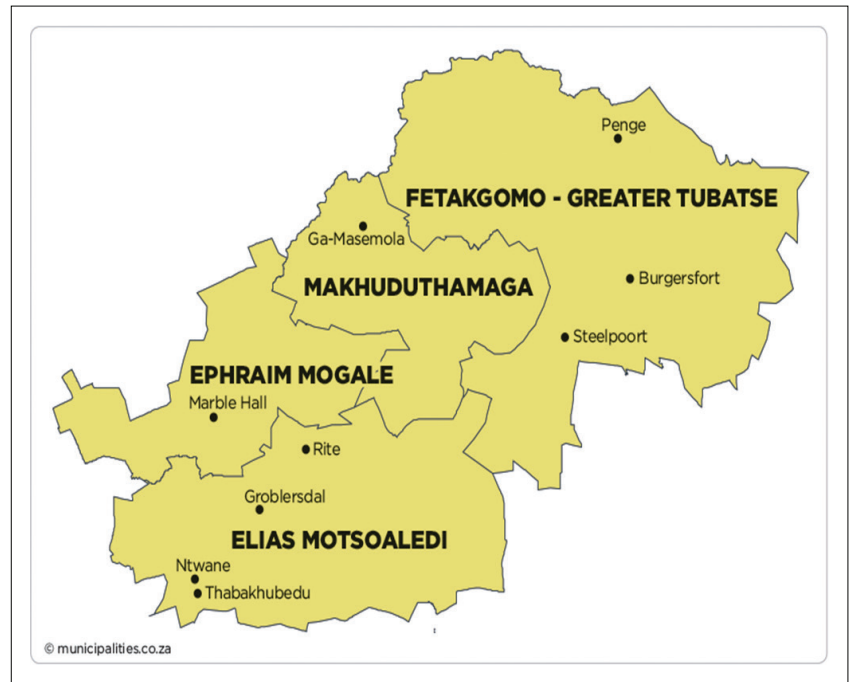

Source: Municipalities of South Africa. Sekhukhune District Municipality (DC47). 2016. [homepage on the Internet]. Available from: https://municipalities.co.za/map/127/sekhukhune-districtmunicipality.

FIGURE 1: Sekhukhune map. ${ }^{15}$

into five subdistricts (i.e. Greater Tubatse, Makhuduthamaga, Ephraim Mogale, Elias Motsoaledi and Fetakgomo). The geographical land distribution is $2096.60 \mathrm{~km}^{2}$, with a population of 274358 according to the 2011 local municipality census (Figure 1). ${ }^{15}$

The following case definitions were used to identify cases. A suspected case was defined as any person who resided in Makhuduthamaga Local Municipality and presented with measured fever of $+38^{\circ} \mathrm{C}$ with acute onset of fever and gastrointestinal symptoms during November and December 2017. A confirmed case was defined as a suspected case who had isolation of typhoidal Salmonella serovars from stool or blood specimens. ${ }^{16}$

\section{Data collection and tools Epidemiological investigations}

An epidemiological investigation was conducted by reviewing clinical records and through a standardised case investigation form (CIF). Collected data included demographics, clinical presentation, laboratory results, travel history, food preparation practices, consumption of restaurant foods, sanitation practices and source of drinking water. Data on the location of the casepatients and the sources of water were collected in January 2018 using the GIS map, focusing on the homes of case-patients, surrounding schools, crèches and sources of water.

\section{Clinical and laboratory investigations}

The clinicians working at the health facilities, where suspected cases presented, collected clinical samples to rule out typhoid fever. National Health Laboratory Services (NHLS) received 106 clinical specimens from 15 November to 31 December 2017. The NHLS microbiology laboratory at Pietersburg Provincial Hospital received blood $(n=65)$, stool $(n=6)$ and rectal swabs $(n=3)$ for culture. In addition, blood samples were collected and Widal tests $(n=32)$ were requested in instances where blood culture bottles were unavailable. 
Six laboratory-confirmed isolates were submitted to the NICD's Centre for Enteric Diseases (CED) for confirmation of a diagnosis of Salmonella Typhi and whole-genome sequencing (WGS) analysis. The CED received bacteria on Dorset-egg transport media [Diagnostic Media Products (DMP), NHLS, Johannesburg, South Africa], and then subcultured onto 5\% blood agar (DMP), to check for viability and purity. Cultures were identified using standard phenotypic microbiological identification and serotyping techniques, which are briefly described here. As required, bacterial colonies were identified using the VITEK-2 COMPACT 15 automated microbial identification system (bioMérieux, Marcy-l'Étoile, France). Serotyping was performed according to the WhiteKauffmann-Le Minor scheme. Antimicrobial susceptibility testing was performed using the VITEK-2 COMPACT 15 system (bioMérieux) and the Etest method (bioMérieux).

For WGS analysis of bacteria, the methodology is briefly outlined here. Genomic DNA was isolated from bacteria using the Qiagen QIAamp DNA Mini Kit (Qiagen, Hilden, Germany). DNA libraries were prepared using a Nextera XT DNA Library Preparation Kit (Illumina, San Diego, CA, USA), followed by a $2 \times 300$ paired-end sequencing runs with $100 \times$ coverage using Illumina MiSeq equipment. Raw data generated on the MiSeq were further analysed using tools available in the CLC Genomics Workbench Software, version 8.5 (Qiagen). Using the 'Trim Sequences Tool', sequence reads were trimmed to include quality trimming, ambiguity trimming and length trimming to discard reads below a length of 50 bases. Trimmed reads were assembled using the 'De novo Assembly Tool'; the assembly algorithm works by using de Bruijn graphs to produce contiguous (contig) sequences (minimum contig length was set at 200 bases). For phylogenetic analysis of bacteria, assembled genome data were analysed using the 'CSI Phylogeny 1.4' on-line analysis pipeline available at the Center for Genomic Epidemiology (CGE) of the Technical University of Denmark (http:/ / www. genomicepidemiology.org/). The CSI Phylogeny pipeline uses various publicly available programs and the analysis steps are briefly described as follows: assembled genome data is aligned against a reference genome and single nucleotide polymorphisms (SNPs) are called; SNPs are filtered and qualified; final qualified SNPs for each genome are concatenated to an alignment; and phylogeny is then inferred based on a comparison of SNP alignments of strains. Single nucleotide polymorphisms were called by alignment and referencing against a South African strain isolated in 2016 (reference number TCD981492). Single nucleotide polymorphism alignments were analysed with iTOL software to generate phylogenetic maximum-likelihood trees.

\section{Environmental investigations}

Water sampling sites were guided by information from casepatients' interviews. Water samples were collected by environmental health practitioners (EHPs) and tested for Salmonella species using polymerase chain reaction (PCR) method at the Council for Scientific and Industrial Research (CSIR) laboratory.

\section{Geographic information system mapping}

Geographic information system (GIS) mapping of the case-patients' locations and water sources was conducted by a trained NICD team and Sekhukhune Department of Health district staff (health promotion coordinator and ward-based outreach team), which was led by a GIS specialist, at all affected villages. Demographic and Global Positioning System (GPS) coordinates were collected and color-coded points were used to indicate cases (confirmed, suspected) and water sources tested for Salmonella species.

\section{Health promotion activities}

Health Promotion activities were conducted during the outbreak through door-to-door consultations, community gatherings at the 13 affected villages, local radio station and primary health facilities. Ward committee councillors were engaged by Sekhukhune outbreak response team to facilitate awareness on food and waterborne illness.

\section{Clinical in-service training activities}

Typhoid fever clinical management training was conducted by District Health Special Program Unit and NICD staff during and after the outbreak. The training was conducted because of observed non-uniformity and challenges on diagnosis and treatment of typhoid fever cases by clinicians.

\section{Data analysis}

Categorical data were summarised as proportions. Descriptive statistics (median and range) were used to describe continuous variables. The epidemic curve was created using the date of onset of symptoms (Figure 2). ${ }^{31}$ Data management and analysis were performed using Microsoft Excel 2016.

\section{Ethical consideration}

The study was approved by the Limpopo Provincial Research Ethics Committee Organization: Office of the Premier (Clearance number: LPREC/19/2018: PG).

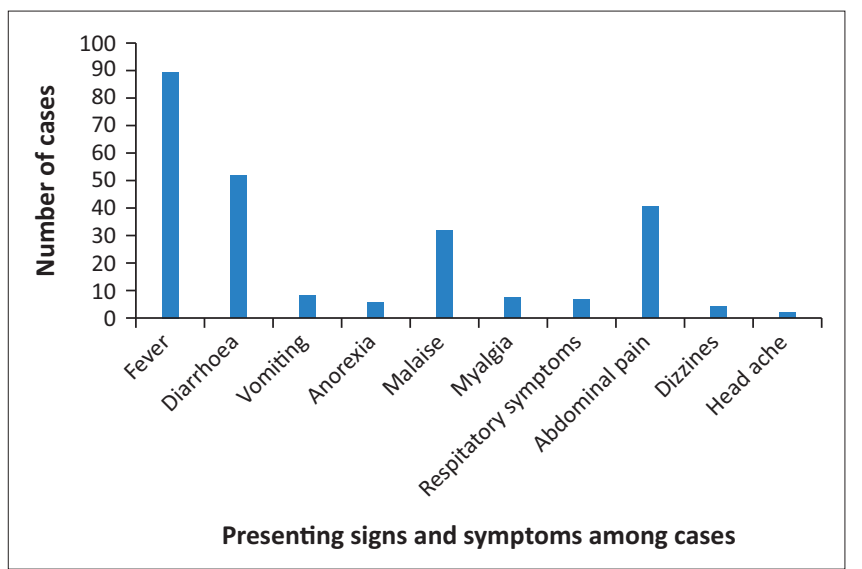

Source: Ramutshila TE, Mabotja MC, Makungo U, et al., Typhoid fever outbreak investigation in Sekhukhune district, Limpopo province, South Africa, November 2017 to January 2018, in National Institute for Communicable Diseases: Division of the National Health Laboratory Service, Public Health Surveillance Bulletin, 2018;16(3): 118-130, viewed n.d. from: https:// www.nicd.ac.za/wp-content/uploads/2019/05/Volume-16-Issue-3-December-2018.pdf

FIGURE 2: Presenting signs and symptoms amongst all cases, Sekhukhune District, Limpopo province, November - December 2017. 


\section{Results}

\section{Epidemiological findings}

Between 15 November and 31 December 2017, a total of 122 cases were reported, of which $6 \%(7 / 122)$ were laboratoryconfirmed for Salmonella Typhi by blood culture. The patient characteristics are described in Table 1 . The median age of the cases was 11 years (range 2-83 years), with most cases between 5 and 14 years $(64 \%, 78 / 122)$. Females accounted for $54 \%(66 / 122)$ of the cases. Majority of cases were from Tswaing village $(67 \%, 82 / 122)$, with four laboratoryconfirmed cases. Most case-patients (67\%, 82/122) reported obtaining water for domestic use from irrigation furrows and other untreated water sources because of interrupted municipal water supply (Table 1). ${ }^{31}$ The common presenting symptoms were fever $(47 \%, 90 / 122)$, diarrhoea $(43 \%, 52 / 122)$ and abdominal pain $(34 \%, 41 / 122)$. The epidemic curve of all the cases by date of onset is presented in Figure $3{ }^{31}$ The epidemic curve suggests the outbreak started in early November and peaked between the second and third weeks.

\section{Laboratory analysis of isolates}

Six isolates were available for WGS analysis, with resulting data showing that five of the six isolates were genetically

TABLE 1: Characteristics of typhoid fever cases, Sekhukhune District, Limpopo province, November - December $2017(N=122)$.

\begin{tabular}{|c|c|c|c|c|c|c|}
\hline \multirow[t]{2}{*}{ Characteristic } & \multicolumn{2}{|c|}{$\begin{array}{l}\text { All cases } \\
(n=122)\end{array}$} & \multicolumn{2}{|c|}{$\begin{array}{l}\text { Suspected cases } \\
\quad(n=115)\end{array}$} & \multicolumn{2}{|c|}{$\begin{array}{c}\text { Confirmed cases } \\
(n=7)\end{array}$} \\
\hline & $n$ & $\%$ & $n$ & $\%$ & $n$ & $\%$ \\
\hline \multicolumn{7}{|l|}{ Age group(years) } \\
\hline$\leq 4$ & 14 & 11 & 13 & 11 & 1 & 14 \\
\hline $5-14$ & 78 & 64 & 76 & 66 & 2 & 29 \\
\hline $15-49$ & 25 & 21 & 22 & 19 & 3 & 43 \\
\hline$\geq 50$ & 5 & 4 & 4 & 4 & 1 & 14 \\
\hline \multicolumn{7}{|l|}{ Gender } \\
\hline Female & 66 & 54 & 62 & 54 & 5 & 71 \\
\hline Male & 56 & 46 & 53 & 46 & 2 & 29 \\
\hline \multicolumn{7}{|l|}{ Residental area } \\
\hline Apelcross & 2 & 2 & 1 & 1 & 1 & 14 \\
\hline Ga-masemola & 6 & 5 & 6 & 5 & 0 & 0 \\
\hline Gaphaahla & 1 & 1 & 0 & 0 & 1 & 14 \\
\hline Tswaing & 82 & 67 & 78 & 68 & 4 & 58 \\
\hline Vlakplaas & 12 & 10 & 12 & 10 & 0 & 0 \\
\hline Strydkraal & 11 & 9 & 10 & 9 & 1 & 14 \\
\hline Other & 8 & 6 & 8 & 7 & 0 & 0 \\
\hline \multicolumn{7}{|c|}{ Health facility consulted } \\
\hline A & 94 & 77 & 92 & 80 & 2 & 29 \\
\hline B & 27 & 22 & 22 & 19 & 5 & 71 \\
\hline C & 1 & 1 & 1 & 1 & 0 & 0 \\
\hline \multicolumn{7}{|l|}{ Water Sources } \\
\hline Stream & 9 & 77 & 7 & 6 & 2 & 29 \\
\hline Irrigation furrow & 70 & 57 & 67 & 58 & 3 & 43 \\
\hline Water tank & 1 & 1 & 1 & 1 & 0 & 0 \\
\hline Borehole & 2 & 2 & 2 & 2 & 0 & 0 \\
\hline Communal taps & 2 & 2 & 1 & 1 & 1 & 14 \\
\hline Well & 1 & 1 & 0 & 0 & 1 & 14 \\
\hline Unknown & 37 & 30 & 37 & 32 & 0 & 0 \\
\hline \multicolumn{7}{|l|}{ Type of toilet } \\
\hline Pit latrine & 110 & 90 & 103 & 90 & 7 & 100 \\
\hline Unknown & 22 & 10 & 22 & 10 & 0 & 0 \\
\hline
\end{tabular}

Source: Ramutshila TE, Mabotja MC, Makungo U, et al., Typhoid fever outbreak investigation in Sekhukhune district, Limpopo province, South Africa, November 2017 National Health Laboratory Service, Public Health Surveillance Bulletin, 2018;16(3): 118-130, viewed n.d. from: https://www.nicd.ac.za/wp-content/uploads/2019/05/ 118-130, viewed n.d. from: https://ww
Volume-16-Issue-3-December-2018.pdf related. Phylogenetic analysis showed that the five related isolates clustered together, with isolates showing <22 SNPs when compared to each other. Of the six isolates sent for WGS, five isolates that were obtained from cases in Tswaing and Strydkraal villages were genetically related $(<22$ SNPs), as shown in Figure $4 .{ }^{31} \mathrm{~A}$ single, un-clustered strain was closely

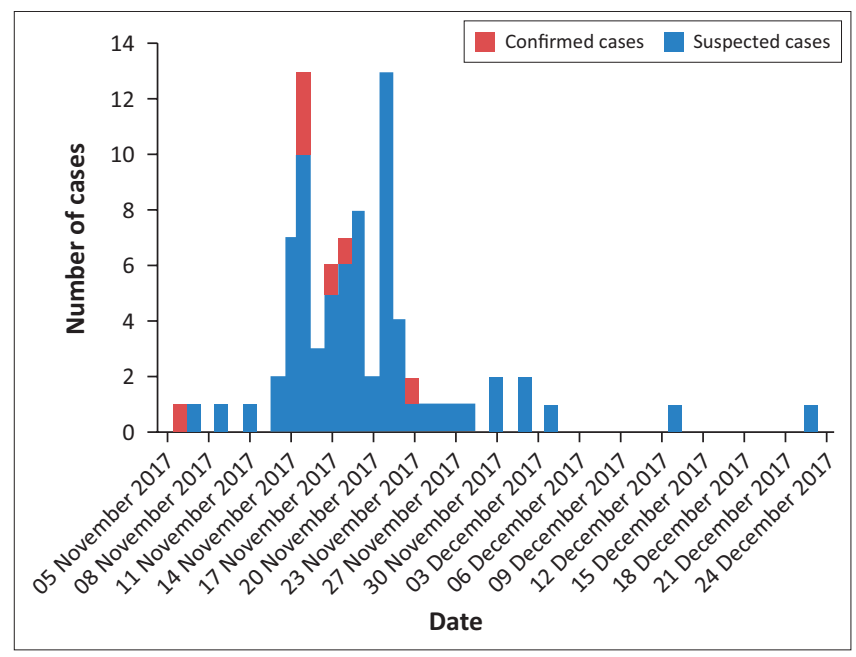

Source: Adapted from Ramutshila TE, Mabotja MC, Makungo U, et al., Typhoid fever outbreak investigation in Sekhukhune district, Limpopo province, South Africa, November 2017 to January 2018, in National Institute for Communicable Diseases: Division of the National Health Laboratory Service, Public Health Surveillance Bulletin, 2018;16(3): 118-130, viewed n.d. from: https://www.nicd.ac.za/wp-content/ 2018;16(3): 118-130, viewed n.d. from: https://ww

FIGURE 3: Epidemic curve of typhoid fever cases (suspected and confirmed) by date of onset, Sekhukhune District, Limpopo province, November - December 2017 ( $N=122)$.

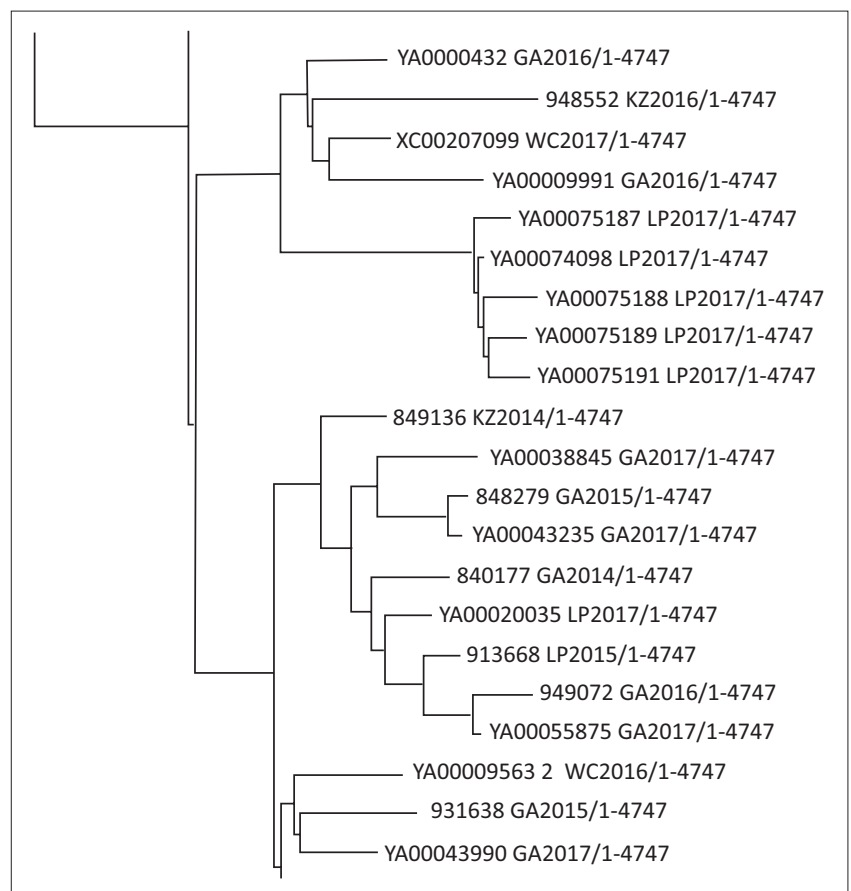

Source: Ramutshila TE, Mabotja MC, Makungo U, et al., Typhoid fever outbreak investigation in Sekhukhune district, Limpopo province, South Africa, November 2017 to January 2018, in National Institute for Communicable Diseases: Division of the National Health Laboratory Service, Public Health Surveillance Bulletin, 2018;16(3): 118-130, viewed n.d. from: https://www.nicd.ac.za/wp-content/uploads/2019/05/ Volume-16-Issue-3-December-2018.pdf

FIGURE 4: Snapshot from a maximum likelihood phylogenetic tree drawn using single nucleotide polymorphism alignments from whole-genome sequencing data of Salmonella Typhi isolates from South Africa. The blocked region highlights a cluster of related isolates sourced at the Sekhukhune District, Limpopo province, November to January 2018. 


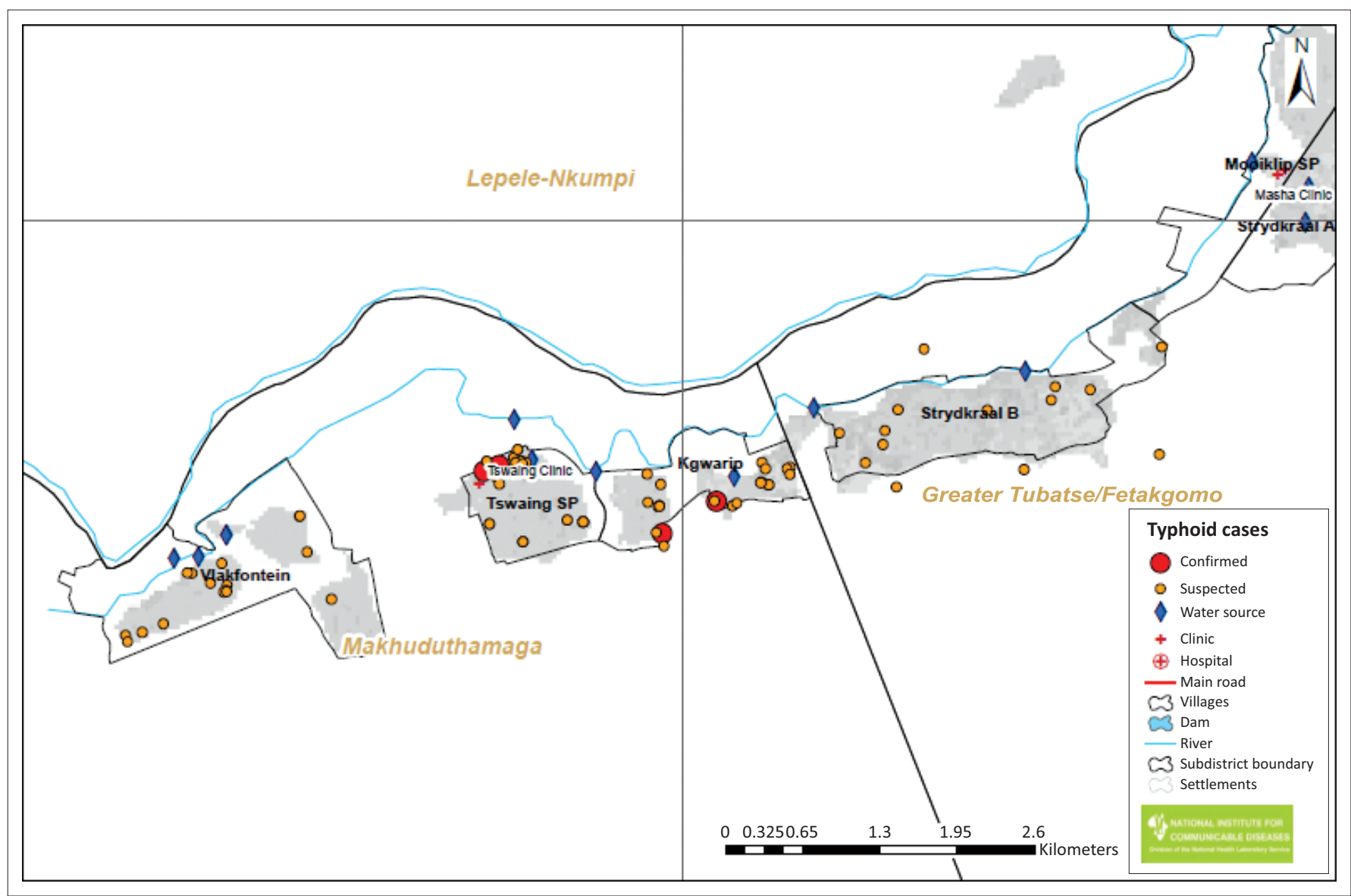

Source: Ramutshila TE, Mabotja MC, Makungo U, et al., Typhoid fever outbreak investigation in Sekhukhune district, Limpopo province, South Africa, November 2017 to January 2018 , in National Institute for Communicable Diseases: Division of the National Health Laboratory Service, Public Health Surveillance Bulletin, 2018;16(3): 118-130, viewed n.d. from: https://www.nicd.ac.za/wp-content/uploads/2019/05/Volume-16-Issue-3-December-2018.pdf

FIGURE 5: Geographic distribution of suspected and confirmed typhoid fever cases and water sources, Sekhukhune District, Limpopo province, November - December 2017.

related to the 2016 Zimbabwe typhoid fever outbreak. All six isolates were susceptible to ciprofloxacin and ceftriaxone.

\section{Environmental findings}

Of the seven confirmed cases, $86 \%(n=6)$ reported using water from the open water sources. Pathogenic Salmonella species were detected in 10/27 (37\%) samples from water sources in the district. The GIS mapping showed clustering of cases in Village S, with 4/7 (57\%) laboratory-confirmed cases and 78/122 (64\%) suspected cases (Figure 5).

\section{Discussion}

This outbreak investigation discovered that rural communities are still at a disadvantage for basic human rights such as safe water and sanitation despite national infrastructure plans in place. Consumption of contaminated water from untreated open sources was the likely driver of infection in this outbreak. This was evidenced by six of the seven laboratory-confirmed cases where water was reported to have been used from open sources for drinking and other household activities. A relation between typhoid fever and contaminated water sources has been identified in other studies. ${ }^{17,18}$ Unsafe disposal of excreta and solid waste might have led to the contamination of open water sources, which has been reported in other settings. ${ }^{19,20}$ The geographical location of water sources sampled in our investigation is in close proximity to villages where cases are clustered. The use of open source drinking water by residents of affected villages is the most likely factor to have resulted in the typhoid fever outbreak. These findings are consistent with results of previous similar outbreak investigations. ${ }^{13,19,21}$

The sudden increase in cases after the start of the investigation was likely because of active community outreach and awareness about typhoid fever signs, symptoms and prevention. A steady decline in cases from the last week of November was probably because of heightened community awareness, high suspicion index at treating hospitals and fixing of the broken down water plant by the local municipality, as well as provision of free water purification products and clean water. This is indicative of how a multisectoral approach impacts mitigation of disease outbreaks. ${ }^{5,22}$ The investigation highlights the importance of consistent safe water supply, and the ability of district surveillance systems to identify and contain outbreaks.

A high burden of typhoid fever is often observed mostly in the paediatric population in low- and middle-income countries. ${ }^{23,24}$ In our study, 75\% (92/122) of the cases were under 15 years of age. Although no deaths were reported 
during this outbreak, a high burden of typhoid fever in children is a public health concern, as there is a $>4$ time's risk of mortality because of increased risk of complications and prolonged hospitalisation that has been observed in other settings. ${ }^{25,26}$ The high burden of typhoid fever amongst children in this study specifies the high-risk population but also enables policymakers and municipal service delivery sectors to make informed decisions on prioritisation of safe water supply in schools and the community in general.

Knowledge about typhoid fever clinical cases management and public health response is fundamental to how well typhoid outbreaks are contained and prevented. Definitive diagnosis of typhoid fever, such as isolation of Salmonella Typhi from blood culture, is largely available and affordable in South Africa. ${ }^{16}$ The use of Widal test may result in misdiagnosis and mismanagement of patients. ${ }^{9,10,27}$ During the investigation period, in-service training on clinical management and public health response of typhoid fever were conducted in the district after it became known that there was no uniformity in patient management amongst clinicians. Typhoid fever management guidelines were distributed to all hospitals to ensure the proper management of patients. ${ }^{16,28}$

\section{Recommendations}

The following recommendations were given to the provincial and local authorities.

- Department of Health, Department of Water Affairs and municipality should form an intersectoral committee that facilitates communication between departments and ensures that challenges pertaining to access to clean water and sanitation are addressed promptly.

- Purification and chlorination of public water supplies should be monitored by the intersectoral health, water and sanitation committee.

- There should be continuous community health education and awareness on water, sanitation and hygiene practices.

- Case management should include contact tracing with an investigation for asymptomatic carriage, documentation of eradication of carriage, and restrictions on food handling practices amongst laboratory-confirmed cases until at least three consecutive negative stool cultures have been taken.

- Health care workers should complete standardised CIFs to ensure that high quality data is collected.

- Department of Health should develop a case control outbreak investigation protocol to guide field workers and to ensure more robust future investigations.

\section{Limitations}

The study had a few limitations. The PCR-based test used by CSIR to test environmental water samples detects all Salmonella enterica subspecies as well as Salmonella bongori, but it cannot distinguish between typhoidal and non-typhoidal Salmonella species. ${ }^{29,30}$

Because of the nature of the cross-sectional study design, we could not determine risk factors that contributed to typhoid fever infection.

\section{Conclusion}

This descriptive study highlights the importance of outbreak investigation and management of typhoid fever cases to ensure disease control. The observed decline of cases further highlights that access to clean water, a multisectoral approach and communication amongst different stakeholders in conjunction with training of health professionals on diagnosis and management of waterborne diseases have an impact on the management of epidemicprone diseases.

\section{Acknowledgements}

All parties mentioned below were involved in the outbreak investigation and response in terms of their departmental expertise:

- Limpopo Department of Health

- Makhuduthamaga Local Municipality

- Sekhukhune District Municipality

- Sekhukhune District: Department of Water Affairs

- Sekhukhune District: Outbreak response teams

- Limpopo province: Outbreak response team

- Makhuduthamaga mobile clinic teams

- Makhuduthamaga subdistrict: Community

- National Health Laboratory Services

- National Institute for Communicable Diseases.

\section{Competing interests}

The authors have declared that no competing interests exist.

\section{Authors' contributions}

All authors contributed equally to this work.

\section{Funding information}

This research received no specific grant from any funding agency in the public, commercial or not-forprofit sectors.

\section{Data availability statement}

Anonymised data for this work is available on request.

\section{Disclaimer}

The views and opinions expressed in this article are those of the authors and do not necessarily reflect the official policy or position of any affiliated agency of the authors. 


\section{References}

1. Cole MJ, Bailey RM, Cullis JD, New MG. Spatial inequality in water access and water use in south Africa. Water Policy. 2018;20(1):37-52. https://doi.org/ 10.2166/wp.2017.111

2. Levy K, Smith SM, Carlton EJ. Climate change impacts on waterborne diseases: Moving toward designing interventions. Curr Environ Health Rep. 2018;5(2): 272-282. https://doi.org/10.1007/s40572-018-0199-7

3. Zolnikov TR. Climate change: Water and sanitation. In: Brears RC, editor. Climate resilient water resources management [homepage on the Internet]. Cham: Springer International Publishing; 2018 [cited 2020 Aug 29]. p. 5-14 (Palgrave Springer International Publishing; 2018 [cited 2020 Aug 29]. p. 5-14 (Palgrave
Studies in Climate Resilient Societies). Available from: https://doi.org/10.1007/ Studies in Climate Resile
978-3-319-78896-8_2

4. Meissner R, Steyn M, Moyo E, et al. South African local government perceptions of the state of water security. Environ Sci Policy. 2018;87(1):112-127. https://doi. org/10.1016/j.envsci.2018.05.020

5. Bridge JW, Oliver DM, Chadwick D, et al. Engaging with the water sector for public health benefits: Waterborne pathogens and diseases in developed countries. Bull World Health Organ. 2010;88(1):873-875. https://doi.org/10.2471/BLT.09.072512

6. Mogasale VV, Ramani E, Mogasale V, Park JY, Wierzba TF. Estimating typhoid fever risk associated with lack of access to safe water: A systematic literature review. J Environ Public Health. 2018. Article ID: 9589208. https://doi.org/10.1155/2018/9589208

7. Stadtländer CK. Control of communicable diseases manual. 18th ed. In: Heymann, DL, editor. Washington DC: American Public Health Association; 2004.

8. Crump JA, Sjölund-Karlsson M, Gordon MA, Parry CM. Epidemiology, clinical presentation, laboratory diagnosis, antimicrobial resistance, and antimicrobial
management of invasive Salmonella infections. Clin Microbiol Rev. management of invasive Salmonella infections. Clin
2015;28(4):901-937. https://doi.org/10.1128/CMR.00002-15

9. Ley B, Mtove G, Thriemer K, et al. Evaluation of the Widal tube agglutination test for the diagnosis of typhoid fever among children admitted to a rural hdospital in Tanzania and a comparison with previous studies. BMC Infect Dis. 2010;10(1):180 https://doi.org/10.1186/1471-2334-10-180

10. Mawazo A, Bwire GM, Matee MIN. Performance of Widal test and stool culture in the diagnosis of typhoid fever among suspected patients in Dar es Salaam, Tanzania. BMC Res Notes. 2019;12(1):316. https://doi.org/10.1186/s13104-019-4340-y

11. World Health Organization. Typhoid [homepage on the Internet]. 2018 [cited 2020 Aug 28]. Available from: https://www.who.int/immunization/diseases/typhoid/en/

12. Keddy KH, Smith AM, Sooka A, et al. The burden of typhoid fever in South Africa: The potential impact of selected interventions. Am J Trop Med Hyg. 2018;99 (3_Suppl):55-63. https://doi.org/10.4269/ajtmh.18-0182

13. Waner S, Kfir R, Idema GK, et al. Waterborne outbreak of typhoid fever in Delmas. S Afr J Epidemiol Inf. 1998;13(1):53-57.

14. National Department of Health. Typhoid cases in South Africa and Gauteng Province [homepage on the Internet]. 2016 [cited 2020 Aug 30]. Available from: https://www. google.com/url?sa=t\&rct=j\&q=\&esrc=s\&source=web\&cd=\&ved=2a hUKEwj_yva3m6fsAhV5UhUIHSK-B8IQFjAAegQIARAC\&url=https\%3A\%2F\%2Fp mg.org.za\%2Ffiles\%2F160309Typhoid.pptx\&usg=AOvVaw2dseSTB2kQw6KSH5Rd ejal

15. Municipalities of South Africa. Sekhukhune District Municipality (DC47). 2016 [homepage on the Internet]. Available from: https://municipalities.co.za/ map/127/sekhukhune-district-municipality

16. Typhoid recommendation for diagnosis, management, and public health response [homepage on the Internet]. 2016 [cited 2020 Aug 29]. Available from: http:// www.nicd.ac.za/assets/files/guideline
17. Swaddiwudhipong W. A common-source water-borne outbreak of multi-drugresistant typhoid fever in a rural Thai community. J Med Assoc Thai. 2001; 84(11):1513-1517.

18. Bhunia R, Hutin $Y$, Ramakrishnan R, Pal N, Sen T, Murhekar M. A typhoid fever outbreak in a slum of South Dumdum municipality, West Bengal, India, 2007: Evidence for foodborne and waterborne transmission. BMC Public Health. 2009;9(1):115. https://doi.org/10.1186/1471-2458-9-115

19. Davis WW, Chonzi $P$, Masunda KP, et al. Notes from the field: Typhoid fever outbreak-Harare, Zimbabwe, October 2016-March 2017 MMWR Morb Mortal Wkly Rep. 2018;67(11):342. https://doi.org/10.15585/mmwr.mm6711a7

20. A large and persistent outbreak of typhoid fever caused by consuming contaminated water and street-vended beverages: Kampala, Uganda. BMC Public Health [homepage on the Internet]. 2015 [cited 2020 Aug 29]. Available from: https://bmcpublichealth.biomedcentral.com/articles/10.1186/s12889from: https:

21. Farooqui A, Khan A, Kazmi SU. Investigation of a community outbreak of typhoid fever associated with drinking water. BMC Public Health. 2009;9(1):476. https:// doi.org/10.1186/1471-2458-9-476

22. Raviglione $M$, Maher $D$. Ending infectious diseases in the era of the Sustainable Development Goals. Porto Biomed J. 2017;2(5):140-142. https://doi.org/10.1016/ j.pbj.2017.08.001

23. Roy JS, Saikia L, Medhi M, Tassa D. Epidemiological investigation of an outbreak of typhoid fever in Jorhat town of Assam, India. Indian J Med Res. 2016;144(4): 592-596. https://doi.org/10.4103/0971-5916.200902

24. Antillón M, Warren JL, Crawford FW, et al. The burden of typhoid fever in low-and middle-income countries: A meta-regression approach. PLoS Negl Trop Dis. 2017;11(2):e0005376. https://doi.org/10.1371/journal.pntd.0005376

25. Azmatullah A, Qamar FN, Thaver D, Zaidi AK, Bhutta ZA. Systematic review of the global epidemiology, clinical and laboratory profile of enteric fever. J Glob Health. 2015;5(2):020407. https://doi.org/10.7189/jogh.05.020407

26. Singh KG, Sundar JS. A study on clinical profile of typhoid fever at Government General Hospital, Nizamabad, Telangana, India. Int J Contemp Pediatr. 2019;6(6):2642. https://doi.org/10.18203/2349-3291.ijcp20194746

27. Wam EC, Arrey CN, Sama LF, Agyingi LA, Wam AN. Comparative study on the use of Widal test to stool culture in the laboratory diagnosis of typhoid fever in Holy Family Hospital Akum, North West Region of Cameroon. Open Microbiol Family Hospital Akum, North West Region of Cameroon. Open
J. 2019;13(1):73-80. https://doi.org/10.2174/1874285801913010073

28. THD. Environmental scarcity and violent conflict: The case of South Africa [homepage on the Internet]. Thomas Homer-Dixon; 1998 [cited 2020 Aug 29]. Available from: https://homerdixon.com/environmental-scarcity-and-violentAvailable from: https://home
conflict-the-case-of-south-africa/

29. Malorny B, Hoorfar J, Bunge C, Helmuth R. Multicenter validation of the analytical accuracy of Salmonella PCR: Towards an international standard. Appl Environ Microbiol. 2003;69(1):290-296. https://doi.org/10.1128/aem.69.1.290-296.2003

30. Gal-Mor O, Boyle EC, Grassl GA. Same species, different diseases: How and why typhoidal and non-typhoidal Salmonella enterica serovars differ. Front Microbiol. 2014;5(1):391. https://doi.org/10.3389/fmicb.2014.00391

31. Ramutshila TE, Mabotja MC, Makungo $U$, et al., Typhoid fever outbreak investigation in Sekhukhune district, Limpopo province, South Africa, November 2017 to January 2018, in National Institute for Communicable Diseases: Division of the National Health Laboratory Service, Public Health Surveillance Bulletin, of the National Health Laboratory Service, Public Health Surveillance Bulletin,
2018;16(3): 118-130, viewed n.d. from: https://www.nicd.ac.za/wp-content/ uploads/2019/05/Volume-16-Issue-3-December-2018.pdf 